In addition to the need for special media, the laboratory should always be informed when tularemia is suspected because of the potential hazard to laboratory personnel. Suspected isolates should be confirmed by the CDC or USAMRIID through local or state health departments.

Effective therapy includes streptomycin, gentamicin, tetracycline, and chloramphenicol; postexposure prophylaxis with tetracycline or doxycycline may be considered. The benefits of tetracycline therapy may outweigh the risks for children younger than 8 years in select clinical situations, including tularemia. ${ }^{16} \mathrm{~A}$ live-attenuated vaccine for preexposure use is available through USAMRIID.

\section{BOTULISM}

There are seven distinct but related neurotoxins, A through $\mathrm{G}$, produced by different strains of Clostridium botulinum, an anaerobic gram-positive rod. Classic neuroparalytic disease is acquired through ingestion of preformed neuro-toxin. Other forms include localized infection (wound botulism) and $C$ botulinum intestinal colonization in infants with in vivo toxin production (infant botulism). Botulism is most often seen in the United States in small clusters or single cases associated with home-canned foods. Although airborne transmission of botulinum neurotoxin does not occur naturally, aerosolization of preformed toxin would be the most likely route of transmission in a bioterrorism event. ${ }^{3}$ Sabotage of food supplies is also possible. Botulism is not transmitted from human to human. Standard Precautions are recommended for hospitalized patients.

The incubation period for foodborne botulism is generally 12 to 36 hours (range, 6 hours to 8 days). Clinical manifestations of disease acquired by inhalation would be the same as those for foodborne botulism. Early manifestations include blurred vision, diplopia, and dry mouth.

Later clinical features indicative of more severe disease include dysphonia, dysarthria, dysphagia, ptosis, and symmetrical, descending, progressive muscular weakness, with respiratory failure. Clinical suspicion is critical, since a recognized source of exposure may be absent in a biological attack. Botulism is a reportable disease.
A toxin neutralization bioassay in mice is used to identify botulinum toxin in serum, stool, or food. $C$ botulinum also may be isolated from stool and food. Electromyography can be helpful diagnostically. Botulinum antitoxin of equine origin available from the CDC and state or municipal health departments should be administered as soon as possible to patients symptomatic with botulism (after testing for hypersensitivity to equine sera).

\section{REFERENCES}

1. Henderson DA. Bioterrorism as a public health threat. Emerg Infect Dis 1998;4:488-492.

2. McDade JE, Franz D. Bioterrorism as a public health threat. Emerg Infect Dis 1998;4:493-494.

3. Franz DR, Jahrling PB, Friedlander AM, McClain DJ, Hoover DL, Bryne WR, et al. Clinical recognition and management of patients exposed to biological warfare agents. JAMA 1997;278:399-411.

4. Christopher GW, Cieslak TJ, Pavlin JA, Eitzen EM Jr. Biological warfare. A historical perspective. JAMA 1997;278:412-417.

5. Henderson DA, Inglesby TV, Bartlett JG, Ascher MS, Eitzen E, Jahrling $\mathrm{PB}$, et al. Smallpox as a biological weapon: medical and public health management. Working Group on Civilian Biodefense. JAMA 1999;281:2127-2137.

6. LaForce FM. Anthrax. Clin Infect Dis 1994;19:1009-1014.

7. Pile JC, Malone JD, Eitzen EM, Friedlander AM. Anthrax as a potential biological warfare agent. Arch Intern Med 1998;158:429-434.

8. Inglesby TV, Henderson DA, Bartlett JG, Ascher MS, Eitzen E, Friedlander AM, et al. Anthrax as a biological weapon: medical and public health management. Working Group on Civilian Biodefense. JAMA 1999;281:1735-1745.

9. Meselson M, Guillemin J, Hugh-Jones M, Langmuir A, Popova I, Shelokov A, et al. The Sverdlovsk anthrax outbreak of 1979. Science 1994;266:1202-1208.

10. Centers for Disease Control and Prevention. Bioterrorism alleging use of anthrax and interim guidelines for management-United States, 1998. MMWR 1999;48:69-74.

11. Centers for Disease Control and Prevention. Prevention of plague: recommendations of the Advisory Committee on Immunization Practices (ACIP). MMWR 1996;45(RR-14):1-15.

12. Centers for Disease Control and Prevention. Fatal human plagueArizona and Colorado, 1996. MMWR 1997;46:617-620.

13. Mann JM, Shandler L, Cushing AH. Pediatric plague. Pediatrics 1982;69:762-767.

14. Evans ME, Gregory DW, Schaffner W, McGee ZA. Tularemia: a 30-year experience with 88 cases. Medicine (Baltimore) 1985;64:251-269.

15. Jacobs RF, Narain JP. Tularemia in children. Pediatr Infect Dis 1983;2:487-491.

16. Leggiadro RJ. Tetracycline for Rocky Mountain spotted fever. Pediatrics 1991;87:124-125.

\title{
HCV Common Among US Veterans
}

\section{Gina Pugliese, RN, MS Martin S. Favero, PhD}

Among veterans who received routine outpatient care at San Francisco Veterans' Affairs Medical Center, the prevalence of hepatitis $\mathrm{C}$ virus (HCV) infection is $18.8 \%$, according to the results of a recent screening study presented by Wright and colleagues at the 50th annual meeting of the American Association for the Study of Liver Diseases. The single greatest risk factor for $\mathrm{HCV}$ was intravenous drug abuse. Other risk factors included tattooing, needlestick associated with service as a medical-team member, and incarceration in jail lasting more than 48 hours.

It was reported that the Veterans' Administration has developed preliminary plans to conduct a national study designed to determine the incidence of $\mathrm{HCV}$ among veterans and has approved the use of combination therapy with interferon and ribavirin for treatment of HCV-infected veterans.

FROM: Wright TL, Briggs ME. Hepatitis $C$ virus infection common among US veterans. Presented at the 50 th Annual Meeting of the American Association for the Study of Liver Diseases; November 5-9, 1999; Dallas, Texas. 